\title{
SPINAL COMPRESSION IN ACHONDROPLASIA
}

\author{
D. O. Hancock, F.R.C.S., and D. G. Phillips, F.R.C.S. \\ South Western Regional Neurosurgical Department, Frenchay Hospital, Bristol
}

Two basic mechanisms are described in the literature as responsible for impairment of neurological function in this condition: narrowing of the spinal canal (Table I), particularly in its antero-posterior diameter, and the development in some cases of severe angulation at the dorso-lumbar junction. The narrowing is directly related to premature fusion of the pedicles to the laminae (Donath \& Vogl, 1925). These and other authors describe how spinal straightening is also impaired because of the disturbance of cartilage growth (Duvoisin \& Yahr, 1962). Lumbar spines may be unusually lordotic, straight, or show diffuse or localised kyphosis. The lumbo-sacral angle may be unusually acute.

TABLE I

Sagittal Measurements at C6 Level (in mm.)

\begin{tabular}{|c|c|c|c|c|c|c|c|}
\hline Normal & Case I & Case 2 & Case 3 & Case 4 & Case 5 & Case 7 & Case 8 \\
\hdashline I7 & I2 & I4 & I4 & I5 & I5 & I2 & I3 \\
\hline
\end{tabular}

Normal as given in Wolf's paper; tube distance from plate 72 inches.

Tube-plate distance in Frenchay cases varied between 36 inches and 72 inches.

Other factors may further constrict the canal. The short vertebral bodies are enlarged at their upper and lower ends, giving a scalloped appearance to the canal in lateral radiographs. The intervertebral discs are hypertrophic. Pedicles and laminae are thickened. Osteophyte formation may occur at the insertion of the annulus fibrosus posteriorly and at the apophyseal points. Wedging of vertebrae at the dorso-lumbar junction is not uncommon. There may be protrusion of intervertebral discs (Spillane, I952; Schreiber \& Rosenthal, I952). Lumbar puncture may be difficult and lumbar myelography unsatisfactory. Descending myelography by the cisternal route is more helpful but may also be very incomplete. The medium may be held up at several levels and may take several days to attain its final resting place (Weber, I953). A complete block in the lumbar region is common where lateral views show the contrast fixed behind the concave posterior aspects of the bodies, giving a characteristic biconvex shadow (fig. I).

Records in the literature of cases of achondroplasia with cord and cauda equina compression are still relatively few, while accounts of successful treatment are still fewer, mostly of isolated cases. Spillane (I952) and Schreiber and Rosenthal (1952) each described successful results of removal of prolapsed lumbar intervertebral discs in achondroplasic dwarfs. Vogl and Osborne (I949) added one case to others from the literature, with constriction at the level of wedged dorso-lumbar vertebrae, as well as the lower lumbar and lumbo-sacral levels. Duvoisin and Yahr (1962) mention operative decompression in four cases with 


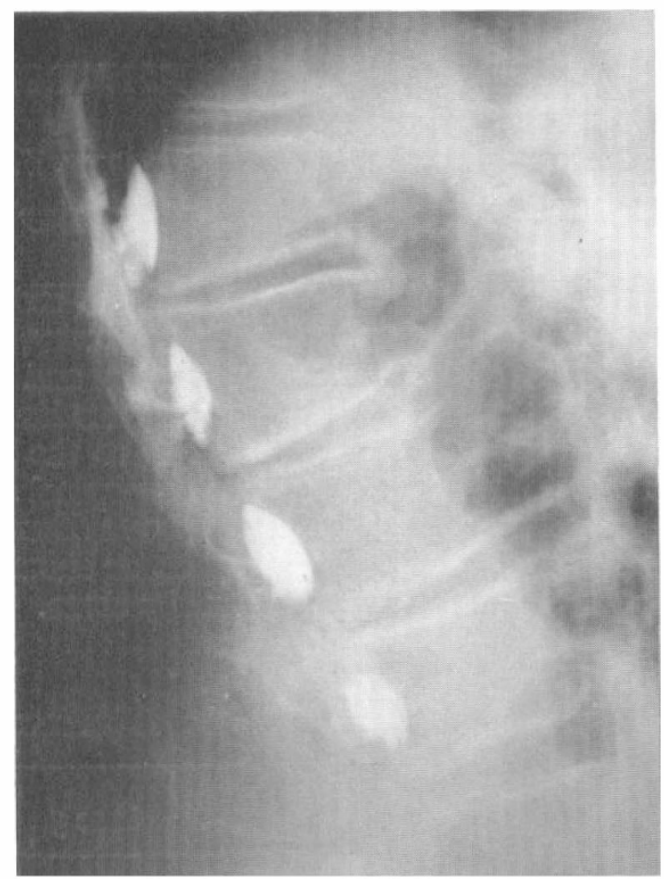

FIG. I

The biconvex appearance of myodil illustrates the narrowness of the spinal canal (Case 4).

poor results. They doubt the validity of Vogl and Osborne's hypothesis of compression of the anterior spinal artery. While recognising that surgical decompression can relieve radicular pain and arrest progression of neurological defect, they emphasise that it must be performed before significant neurological disability has developed. They say there is not yet a sufficient surgical experience to provide a basis for selecting the best procedure for each patient. While a local procedure may suffice, including the segment above the gibbus as recommended by Vogl and Osborne, there must be 'an adequate decompression, ... . extensive if not complete lumbar laminectomy'.

Our series of eight cases all treated by operation provides further general experience, mainly of advanced cases, and in particular illustrates difficulties in assessing the extent of the compression, the appropriate extent of operation and indeed, in the worst cases, the benefit to be expected. All these patients (except Case 6) were typical achondroplasic dwarfs.

\section{CASE REVIEW}

Case I. C. P., female, aged 5 I years. She became tetraplegic immediately after a fall from a I 5-feet high wall in July I954. For the previous six months she had suffered from numbness and weakness of the lower limbs after walking.

On admission to the neurosurgical unit three weeks after injury, examination showed 
gross weakness of all four limbs, with total paralysis of both hands and toes and limited hypoalgesia in the left upper and both lower limbs. Tendon jerks were mainly sluggish or absent, and plantars extensor. She was incontinent of urine.

Skull radiographs showed marked basilar impression, the tip of the odontoid being II millimetres above Chamberlain's line. Spinal radiographs showed wedging of the body of the first lumbar vertebra. There was osteophyte formation in the cervical vertebrae but no lumbar lordosis.

Lumbar puncture was performed with great difficulty, only a few drops of cerebrospinal fluid being obtained. Cerebrospinal fluid protein was I60 mg. per cent. Cisternal myelography revealed a complete block at the C7-Di level.

She improved with rest, and five weeks after admission the fifth, sixth and seventh cervical laminae were removed. Ridging of the anterior wall of the spinal canal was confirmed at the C5-6, C6-7 and C7-Di levels and underlying the root sleeves. The projections were reduced and found to consist of bone and disc material. The dura was opened and the cord appeared to be normal. No improvement followed, and on Io November I954 a further descending myelogram was performed. Myodil was held up at the occipito-atlantal level, descending to $\mathrm{C}_{2}$ when the neck was flexed, apart from a few drops which reached the lower cervical level.

On I2 November I954, at a suboccipital decompression, the foramen magnum was found to be invaginated and the dura grooved by the arch of the Atlas. The laminae of the upper four cervical vertebrae were removed. On opening the dura the cord was seen to be narrowed at the first and second segments; the spinal canal was also narrowed. Postoperatively the patient's condition deteriorated, with a bilateral complete facial palsy, total bilateral ophthalmoplegia and tetraplegia. She died five days later.

Post-mortem examination showed a narrowed foramen magnum. A haemorrhage was present in the cervical cord at the second segment and the medulla was softened.

Comment. Basilar impression of the skull accompanied the spinal abnormality. All four limbs were severely affected. Though there had been premonitory symptoms, the main syndrome was acute and severe immediately following a fall. Autopsy revealed intrinsic damage in the cervical cord so that the prognosis was likely to have been bad from the beginning.

Case 2. A. D., male, aged 63 years. Three years before admission to hospital, after sleeping in a chair he awoke with loss of use of both legs and pain in the back. He remained in bed for a fortnight and needed crutches thereafter. Over the course of a year the back pain radiated downwards to involve both knees. Weakness slowly progressed, until he was confined to a chair. Shortly before admission to the neurosurgical unit he became incontinent of urine.

On examination he was found to have absence of normal lumbar lordosis with a fixed lumbar spine. The upper limbs were normal apart from absent reflexes. Adductor spasm was present in both lower limbs; the only voluntary movement on the right was hip flexion. He had a flaccid paralysis of both ankles and feet and there was neither hip extension nor knee flexion on the left. The knee jerks were exaggerated, ankle jerks absent and plantar responses extensor. Anaesthesia of the first sacral dermatome was present on both sides, with hypoalgesia below and sparing of the third and fourth sacral dermatomes. Position sense was absent below the knees and vibration sense below the iliac crests.

Radiography of skull and cervical spine showed basilar impression. There was kyphosis of the lumbar spine, accentuated by sitting, and wedging of the twelfth dorsal and first and second lumbar vertebrae. The disc spaces were large except at L2-3 and DI2-LI, these two being narrowed with sclerotic margins.

Lumbar puncture elsewhere had failed and cisternal myelography was performed. The myodil was fixed on either side of the upper four lumbar disc spaces (fig. 2). Temporary urinary retention occurred subsequently, with faecal incontinence. 
On 24 October 1956, all the lumbar laminae were removed, the canal being very narrow, so much so that it would have been 'difficult and perhaps damaging to have tried to deal with any of the disc protrusions'. The dura was partly opened to reveal an arachnoiditis, although the roots of the cauda equina could be separated. The dura was sutured.

After operation slight motor and sensory improvement occurred and the ankles remained flaccid. He remained chair-bound to the time of his death in March 1959. There was no post-mortem examination.

Comment. Basilar impression was also present. Slowly progressive symptoms and signs were restricted to the lower limbs but there was a combination of upper and lower motor neurone palsy. As in the previous

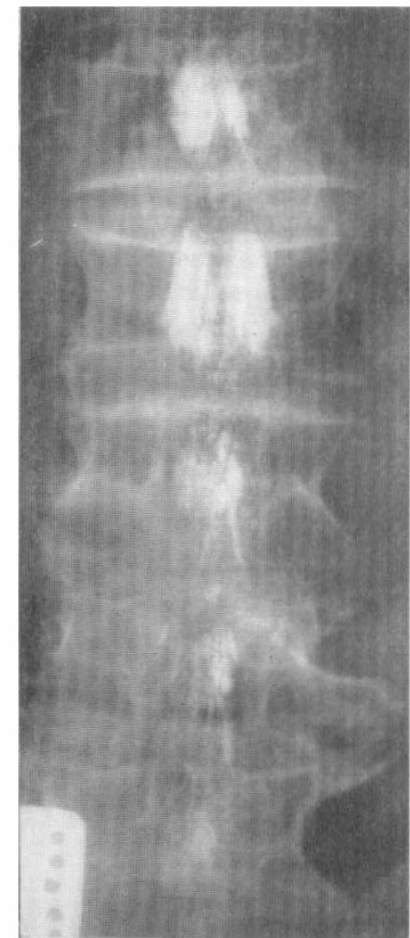

FIG. 2

The obstructed flow of dye at each interspace is shown (Case 2). It may take as long as forty-eight hours to obtain full descent of the myodil. case, lumbar puncture was unsatisfactory and cisternal myelography had to be performed. Though no block was demonstrated above the lumbar region, laminectomy here (which revealed arachnoiditis) was followed by only minimal improvement.

Case 3. G. C., male, aged 53 years. He presented with a year of increasing weakness in the lower limbs, worse after walking. There was intermittent numbness and coldness in the feet. He started to fall shortly before his admission early in December 1956.

On examination he was found to have an accentuated lumbar lordosis, and the upper limbs were normal apart from absent supinator reflexes. A moderate paraparesis with exaggerated reflexes and extensor plantar responses was found. Sensory impairment was confined to the medial aspect of the legs and dorsum of the feet.

Lumbar puncture released a few drops of cerebrospinal fluid. Radiography showed moderate osteophytosis of the lumbar spine, most evident at the L4-5 level. Cisternal myelography showed a small transverse bar at C5-6 and a free flow to Dio; flow was then slow and there was pooling in the scalloped posterior aspect of the lumbar vertebral bodies. No disc protrusion was seen.

At operation the tenth, eleventh and twelfth dorsal and the first lumbar laminae were removed. The canal was small and there was little epidural fat. At the Dio level the dura was adherent to the arachnoid and when fully opened the tightly packed roots were immediately extruded. The dura was left open.

Urinary retention occurred post-operatively, though lower limb movements were unaltered. At the time of discharge subjective numbness had cleared up. Subsequently power in the legs and sphincter control returned to normal. The patient returned to work in May 1957, but within two years weakness recurred, affecting the ankles most notably. Minimal sensory loss over the feet was also noted.

A further descending myelogram in November 1959 showed a block at the interspace between $\mathrm{L}_{2}$ and $\mathrm{L}_{3}$. The laminectomy was extended down to include the fourth lumbar vertebra. The roots were crowded and adherent to each other. The dura was left open.

Limited improvement followed this operation. He returned to work and remains employed. A slow regression is now occurring. 
Comment. Another slowly progressive lesion almost entirely affecting the lower limbs. Upper motor neurone signs were present and there were similar findings at repeated cisternal myelography. Improvement followed dorso-lumbar decompression; relapse occurred after two years with limited and temporary improvement after lower lumbar laminectomy. Arachnoiditis was again found in the cauda equina.

Case 4. D. E., male, aged 6I years. Paroxysmal tingling occurred in both legs two years before admission; he noticed weakness, especially after walking. The weakness slowly progressed, and he was using a stick for a year. There had been involuntary jerking of one leg for a year. Seven weeks before admission he noticed the hands had become stiff and weak. Micturition was normal.

On admission in August 1960 hand grips were poor and the intrinsic hand muscles wasted. Wrist extension was weak. Right knee and plantar flexion were weak and hip flexion absent. Lower-limb tendon reflexes were absent. The right plantar response was flexor, the left extensor. Position sense was lost in all digits and vibration sense absent in both lower limbs and the right upper limb.

Lumbar puncture released a few drops of cerebrospinal fluid. Radiographs of the cervical spine showed extensive osteophytosis and narrowing of the C6-7 interspace; the spinal canal was narrowed. The dorsal spine had osteophytes on the lower margin of the body of Dir, with wedging of the body of Di2. There was scalloping of the lumbar vertebral bodies posteriorly and generalized osteophytosis.

Lumbar myelography showed contrast material fixed behind each lumbar body (fig. I). Cisternal myelography showed the downward flow of myodil was very slow throughout the length of the canal; it did not descend below the L3-4 level and bars were present at the $\mathrm{C}_{4}-5$ and $\mathrm{C}_{5}-6$ levels. A day later rescreening showed no further descent of the myodil.

Laminectomy of the fourth, fifth and sixth cervical vertebrae was performed in September 1960. A high-speed pneumatic drill was used to widen the decompression. The canal was narrow and epidural fat was absent except at the upper and lower margins of the exposure. The denticulate ligaments were divided at three levels on either side and the dura left open. The laminae from L2 to $S_{I}$ inclusive were then removed; the canal here was also small ('a narrow deep cleft') and the laminae were in close contact with the dura, which was not opened. Acute angulation was present between the last lumbar lamina and the sacrum. Urinary retention occurred post-operatively.

Following this operation the power in the left lower limb worsened. Flexor spasms were troublesome and, as improvement occurred, in November I 960 the last cervical and upper four dorsal laminae were removed. A prominent disc at the $\mathrm{C}_{7}$-DI interspace was incised but only a few very small fragments of fibrous tissue could be removed, i.e. there was no real disc prolapse. Three denticulate ligaments were divided on each side. The dura was left open.

In January I96I a transurethral resection of the bladder neck was done for urinary obstruction. In this interval the only improvement had occurred in the right-hand grip. Analgesia was now complete below the Di level.

In February I96I the fifth dorsal to the first lumbar laminae were removed. No particular level of compression was discovered, the canal being narrow throughout. The dura was opened completely.

By June no further motor improvement had occurred and he was discharged to another hospital where he died in November of bronchopneumonia.

Comment. A slowly progressive lesion involving the lower limbs, then the upper. Lumbar and cisternal myelography suggested generalised constriction. Three operations were performed with, finally, laminectomy of the whole spine from $\mathrm{C}_{4}$ to $\mathrm{S}_{\mathrm{I}}$. This did not result in any significant improvement. 
Case 5. P. W., female, aged 50 years. She presented with a five-year history of progressive stiffness and numbness of the left leg. The right leg had become involved for only four months. A week after falling downstairs, with forcible neck flexion, she developed a severe paraparesis. There was pain along the radial borders of each forearm and the thumbs. At the referring hospital a cisternal myelogram showed an obstruction in the mid-dorsal region.

A mildly spastic paraparesis was recorded on admission in April 1961, with bilateral extensor plantar responses. Sensory loss was difficult to assess, but joint sense was impaired on both sides. Radiographs showed diffuse osteophytosis of the cervical spine and basilar impression. The lumbar spine was flat and there was no vertebral wedging. Physiotherapy and hydrotherapy were continued until June, by which time she could stand supported. However, weakness had appeared in the upper limbs and the ankles remained very weak. At home again for three months, further deterioration occurred.

In September I96I the fourth to eleventh dorsal laminae were removed with the help of the high-speed dental burr. The dura was adherent to the laminae and was not opened. Small protrusions could be felt anteriorly at the disc levels, but there was no prolapse of disc material. Overnight the blood pressure fell to 60 millimetres systolic, and complete paraplegia was present the next morning.

A further laminectomy was performed three weeks later, after descending myelography had shown partial obstruction at the DI2-LI interspact; the myodil being fixed opposite the bodies of $\mathrm{L}_{\mathrm{I}}$ and L2. The last dorsal and all lumb ar laminae were removed using the high-speed drill. Large prominences were found laterally on the right at the last dorsal and first lumbar discs, the dura being indented by the outgrowths. No disc material could be removed. The dura was not opened.

In August I96I she was transferred to the National Spinal Injuries Centre at Stoke Mandeville. After a period of rehabilitation she returned home in a wheelchair and is now doing housework.

Comment. A slowly progressive lesion, exacerhated by a recent fall, producing severe tetraparesis, unimproved with conservacive treatment. She was the third patient to have basilar impression. Laminecterny at the mid-thoracic level was followed by deterioration possibly attributable to an episode of hypotension. Further laminectomy at a lower level đid not bring about any further improvement.

Case 6. M. J., female, aged 25 years. This patient, unlike all the others in this series, was not a typical achondroplastic dwarf. She showed only mild signs of the condition. She first complained of bar:kache at the age $4 \frac{1}{2}$ years. At this time a dorsolumbar gibbus was present, and advansed wedging of the bodies of D I 2 and L I was visible on radiographs. She was fitted with a plaster jackk:t and a number of these were worn over the next nine years. During this period the kyphosis increased. By October 196I, when she was aged 15 years, pain was radiating down the left leg. Examination in November showed a localised dorso-lumbar kyphosis. She had a tetraparesis with exaggerated reflexes in the lower limbs and Aexor plantar yesponses. There was hypoalgesia of both lower limbs. Radiographs of the cervical and lumbar spine were normal. At the dorsolumbar junction there was a severe angular deformity, with most severe wedging at the first lumbar vertebra.

Cisternal myelography showed a free flow of myodil to the upper border of the kyphus-it descended below the region, pooling behind the vertebral bodies (fig. 3 ).

In December I96I a tibial graft was slotted into the bodies of DI I and L2, the eleventh and twelfth ribs being removed on the left side. She remained in a plaster bed until mid-June I962.

Early in July lower limb power and sensation had improved. The upper limbs remained unchanged. 
Comment. This patient, younger than the others, was not a dwarf and the achondroplasia was of mild degree; the main abnormality was a well-marked localised dorso-lumbar kyphosis present from early childhood and was the only such deformity in this series. The neurological lesion was quite slight, pain being the presenting symptom. This was relieved by rest. A bone graft was performed really as a prophylactic procedure in the hope of preventing further trouble.

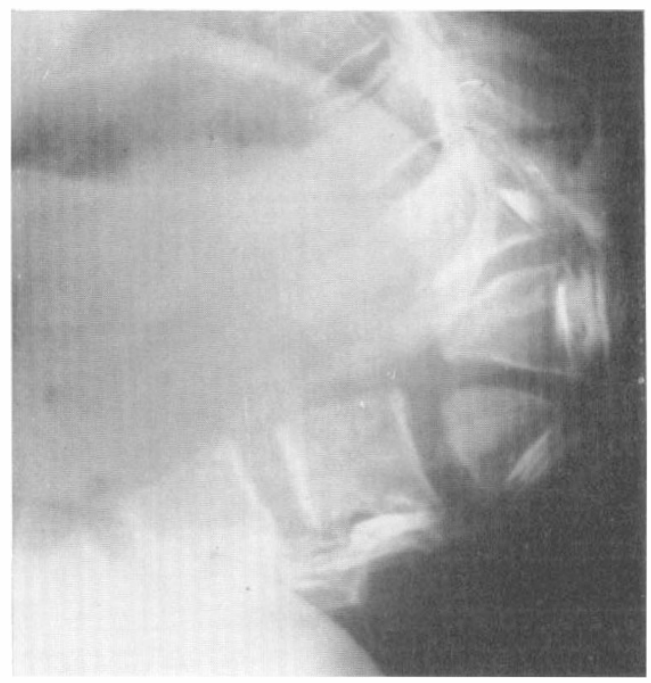

FIG. 3

Severe kyphus with wedging of vertebrae (Case $6)$. In some instances the anterior aspect of the bodies abut one on another.

Case 7. I. R., female, aged 55 years. She gave a four-year history of progressively increasing weakness and numbness of the lower limbs. She was able to walk only a few yards without support. Girdle pains in her lower chest occurred two months before her admission. Sphincter control was unimpaired. An attempt at lumbar myelography at another hospital had failed. There was a spastic paraparesis with exaggerated tendon jerks and extensor plantar responses, but no sensory abnormality.

Radiographs of the cervical spine showed mild osteophytosis. In the dorsal spine some anterior lipping of the bodies was present. The lumbar spine showed lipping on the posterior aspects of the third and fourth vertebrae; there was no wedging of the bodies.

Cisternal myelography in March 1962 revealed a free flow of myodil to the eleventh dorsal region. A little passed below becoming impacted at the second lumbar level.

A week later the laminae of Dro to L2 inclusive were removed. No epidural fat was found and the dura was adherent to the ligamentum flavum. It was opened and sutured to the muscles. Bladder function was unimpaired post-operatively and the power of the lower limbs improved.

In January I964 the patient was walking well, using a stick only out of doors.

Comment. The neurological lesion here, though slowly progressive and not very severe, was confined to the lower limbs. Cisternal myelography showed a free flow to the dorso-lumbar level where laminectomy was performed. Improvement followed and remained over nearly two years. 
Case 8. M. B., male, 38 years. The patient was knocked down by a car two years ago, suffering a fracture of the left femur, which was plated. Since then he was unable to walk because of progressive paraparesis. He was incontinent of urine and faeces, and flexor spasms occurred immediately on standing.

On examination the upper limbs were normal apart from sluggish tendon jerks and slight weakness of dorsiflexion at the wrists. The lower limbs showed frequent involuntary flexion spasms, occasionally with voiding of faeces and urine. Voluntary movements were restricted to the toes. Plantar responses were extensor. There was total analgesia below segmental level LI and relative hypoalgesia over segments DII-I2. Touch was impaired below this level but joint and vibration sense was preserved.

Radiography showed a moderate dorso-lumbar kyphosis with anterior lipping of the bodies of DI 2 and LI, with wedging of these bodies. The sacrum was angulated sharply backwards. Attempts at lumbar and cisternal puncture were unsuccessful and accordingly myelography could not be performed.

In June I 964 laminectomy was performed removing the lower four thoracic and the upper three lumbar laminae. Epidural fat was scanty or absent and the theca clearly had been compressed. At the upper and lower limits of exposure there appeared to be a little more room, though epidural fat was still scanty. The dura did not appear to be unduly tense and was not opened.

Post-operative involuntary movements of the legs were absent. Voluntary power returned progressively to both lower limbs to some degree in all groups. Appreciation of pinprick was regained. Spontaneous micturition was re-established. Seven weeks after operation, however, there was no further progress, flexor spasms had returned and it was clear the patient would remain severely disabled.

Comment. A progressive spastic paraparesis with incontinence followed the road accident. Myelography could not be performed because of failed lumbar and cisternal punctures. A quite extensive laminectomy was done (seven segments) at the dorso-lumbar region, as indicated by his sensory level, and was followed by improvement immediately post-operatively. Further observation indicated that severe disability would remain.

\section{DISCUSSION}

Clinical, radiological and operative findings in this series confirm previously recorded features of the narrowed achondroplasic spinal canal. Apart from one case (Case 6), however, the compression in our cases appeared to be more widespread. In some, serious compression was restricted to the lower end but in others it involved the whole length of the spine (even the foramen magnum), rather than only a localised dorso-lumbar kyphosis. Figure 4 shows interpedicular measurements in our series, compared with the normal range (Elsberg \& Dyke, I934). It is to be noted in four of these that narrowing was extensive, involving upper levels as well as the lumbar region (Cases $I, 5,7,8$ ). This corresponded with the clinical syndrome. In all cases the narrowing was more marked towards the lower end of the lumbar spine (except Case 6, not included in the table). Table I shows consistent anteroposterior narrowing in the cervical spinal canal (satisfactory measurements were not practicable at other levels owing to deformity).

Also in these cases there was no true intervertebral disc prolapse, such as has been described by Spillane (1952) and Schreiber and Rosenthal (1952). It was notable that even in cases where compression appeared to be mainly of the cauda equina with, in two cases, swelling and adhesions of swollen roots suggesting 
arachnoiditis, there were always well-marked signs of an upper motor neurone lesion.

Myelography was hindered by difficulties of lumbar puncture in a small canal. Cisternal puncture was generally successful, but it was not always possible to be

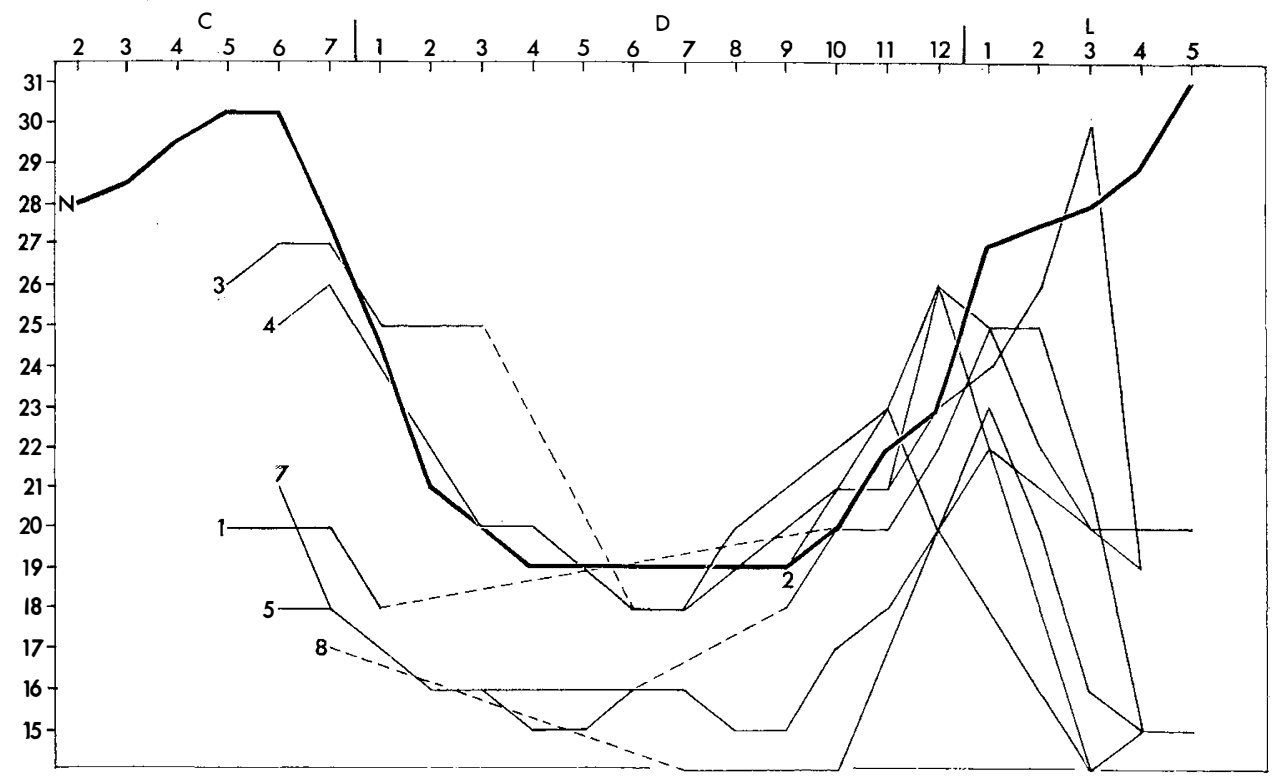

FIG. 4

Spinal interpedicular measurements in cervical, dorsal and lumbar regions (millimetres). Numbers refer to cases in text; $N=$ normal as extrapolated from data in Elsberg and Dyke's paper; tube distance from plate 30 inches.

sure of the extent of significant cord or root compression. We know from experience with cervical spondylosis and more recently with 'lumbar spondylosis' (Verbiest, 1954; Epstein, Epstein \& Levine, I962; Teng \& Papatheodorou, I963; Ehni, I963) that spinal cord and root damage commonly occurs in narrowed canals without complete blockage to the passage of myodil. The features of cervical spondylosis are well known, but lumbar spondylosis is a recent conception, its features consisting of a narrow spinal canal encroached on by thickened ligamenta flava, osteophytes and bulging annular ligaments. Myodil may 'pool' in discrete segments as on the 'scalloped' posterior aspects of the achondroplasic vertebral bodies. Blau and Logue (I96I) have commented on the 'intermittent claudication syndrome' in such cases, with pain after walking set distances relieved by rest. This they attributed to ischaemia of the nerve roots during exercise. A similar mechanism might apply to Cases I, 3 and 4 of this series where pain came on after walking.

The results of treatment have been disappointing. Apart from Case 6, which was exceptional, there was no improvement with conservative management. A sudden severe neurological disability following injury (Cases I and 5) probably means intrinsic neuronal damage with at best marginal recovery possible. On the other hand, one may legitimately hope to halt or even improve with decompression a slowly progressive lesion, provided it is not too advanced. 
Our experience, in contrast to that of some other authors, suggests that unless there is very clear evidence that the compression is localised, laminectomy must be extensive to be adequate. Handling of the patient must be very careful, e.g. to avoid spinal hyperextension at the time of myelography and at induction of anaesthesia. A high-speed cutting burr with a pneumatic motor has been found of great value in performing the laminectomy. It speeds the operation and avoids damage to cord and roots likely to happen when using bone forceps in a constricted canal. The dura should be left widely open. In some cases further operations after an interval may be required.

The chief lesson to be drawn from our experience is the lack of benefit to be expected in advanced cases. If anything is to be achieved by operation it must be advised early in the paretic syndrome, with realisation that any benefit may be limited. All but two of our patients were over 50 years old. It is reasonable to assume that in these cases the compressed spinal cord becomes more vulnerable to ordinary stresses with advancing age. Accidental falls are a further hazard.

The situation in which benefit from even a quite extensive laminectomy is followed by later relapse with need for further operation, with less lasting benefit, is comparable to some cases of advancing spinal compression in Paget's disease. It is a situation of diminishing returns.

With these reservations, we are in agreement with Duvoisin and Yahr (1962), that surgical decompression can confer worthwhile benefit, and in particular that it should be performed early; to wait until serious neurological disability is present is to wait too long.

\section{SUMMARY}

A series of eight operated cases of achondroplasia with spinal compression is reviewed. In advanced cases, particularly after injury, the prognosis is bad. Conservative treatment cannot check the progressive disorder. With appropriate pre-operative study and safeguards, and a recognition that benefit may be limited, early operation is recommended.

\section{ACKNOWLEDGEMENTS}

We are grateful to Mr. G. L. Alexander for permission to quote Case 2, to Mr. A. L. Eyre-Brook to quote Case 6, and to Mr. A. Hulme to quote Cases 3, 7 and 8 . Our thanks are also due to Dr. J. L. G. Thomson for help in radiological interpretation and measurements.

\section{RÉSUMÉ}

Une série de huit malades opérés pour achondroplasie avec compression de la moëlle est présentée. Dans les cas avancés, particulièrement après l'atteinte traumatique, le pronostic est mauvais.

Le traitement conservateur ne peut freiner les désordres progressifs. Avec une étude pré-operatoire et en prenant toutes les précautions voulues, en ayant a l'esprit que les bénefices de l'operation ne sont que limités, l'intervention pratiquée tôt est recommandée.

\section{ZUSAMMENFASSUNG}

Eine Serie von 8 operierten Fällen von Kompression des Rückenmarks bei Achondroplasie wird berichtet. Die Prognose ist schlecht in fortgeschrittenen Fällen, besonders nach Verletzungen. 
Konservative Behandlung kann das Fortschreiten des Prozesses nicht aufhalten. Frühoperation wird empfohlen vorausgesetzt, dass ihr eine gründliche Untersuchung und Vorbehandlung vorausgehen und dass anerkannt wird, dass das Resultat nur teilweise befriedigend sein kann.

\section{REFERENCES}

Blau, J. N. \& Logue, J. (I96I). Lancet, I, IO8I.

Donath, J. \& Vogl, A. (I925). Wien. Arch. inn. Med. Io, I.

Duvorsin, R. C. \& YAHR, M. D. (I962). Neurology (Minneap.), I2, 202.

EhNi, G. (1963). Paper read at foint Meeting of American and British Neurosurgeons, London.

Elsberg, C. A. \& Dyke, C. G. (I934). Bull. neurol. Inst. N.Y. 3, 359.

Epstein, J. A., Epstein, B. S. \& LAvine, L. (1962). F. Neurol. Neurosurg. Psychiat. 15, 246.

SCHREIBER, F. \& Rosenthal, H. (1952). F. Neurosurg. 9, 648.

Spillane, J. D. (1952). F. Neurol. Neurosurg. Psychiat. 15, 246.

Teng, P. \& Papatheodorou, C. (1963). Brit. F. Radiol. 36, 122.

VERBIEST, H. (I954). F. Bone ft. Surg. 36-B, 230.

Vogle, A. \& Osborne, R. L. (I949). Arch. Neurol. Psychiat. 61, 644.

Weber, von G. (1953). Schweiz. Arch. Neurol. Neurochir. Psychiat. 71/72 291.

Wolf, B. S., Khilmani, M. \& Malis, L. (1956). F. Mt. Sinai Hosp. 28, 3. 